\title{
Sudden unexpected infant death in a French county
}

\author{
M WAGNER, D SAMSON-DOLLFUS, AND J MENARD \\ Department of Neurological Investigation, University Hospital, Rouen, France
}

SUMMARY We report a study of sudden unexpected infant death (SUID) in a French county (Seine-Maritime) between 1978 and 1981 (rate of 2.71 per 1000 live births). The results agree with those of previous studies concerning sex ratio, seasonal variation, and peak age of death. No relation between gestational age and age of death was found. A comparison with matched living control infants was performed for 136 of the 207 total deaths for whom computerised medical data were available. Significant differences were found between these two groups in gestational age, birthweight, admission to a paediatric ward at birth, and proportion of single mothers. In analysing birthweight and gestational age separately, the birthweights of SUID cases were significantly lower than those of controls, whatever the gestational age. The converse was not true, however: in classifying infants by birthweight, a significant difference between the gestation period of SUID victims and controls was found only for low birthweight infants (less than $2500 \mathrm{~g}$ ). It is considered that it may be possible to identify infants at particular risk of SUID within the group of babies admitted to hospital at birth for major problems, and a study is currently underway among infants born in Seine-Maritime in 1982.

Epidemiological studies of sudden infant death syndrome (SIDS) have been undertaken in many countries (primarily the United States, Canada, Great Britain, Australia, New Zealand, and Denmark) in the past 30 years, and these include a number of major studies comparing SIDS victims with healthy controls or infants who have died of known causes. In French speaking European countries, however, such investigations are still in a preliminary stage and scarce data comparing SIDS victims with control infants are available. Much research being done in Belgium and France is based on the detailed questionnaire developed in Brussels, by Kahn, ${ }^{1}$ who has recently reported on a comparison between SIDS victims, near miss for SIDS infants, and babies whose parents consulted doctors because of anxiety about SIDS (with no personal or family history of pathology suggesting SIDS). French publications have dealt with a comparison of SIDS and near miss for SIDS babies in the area of Lyons, ${ }^{2}$ and with sudden unexpected infant deaths (SUID) in the Finistère region. ${ }^{3}$

We conducted a study of presumed SIDS deaths in the county (département) of Seine-Maritime (population 1193000 in 1982) between 1978 and 1981 as a follow up to an unpublished study using death certificate data from the same region for the period 1970 to $1977 .{ }^{4}$ In addition to analysis of data from the same source, we attempted to compare some of the 1978-81 infant deaths for whom computerised information based on medical certificates was available with a group of matched living control infants.

\section{Method}

In France necropsies are not performed routinely in all cases of presumed SIDS, and until recently the only results available for analysis were derived from necropsies performed for medico-legal reasons in cases where the death was considered 'suspicious'. For this reason there is still a reluctance on the part of many doctors to suggest a necropsy to parents who have just lost a baby to presumed SIDS.

Since 1980 in the Rouen metropolitan area (population 379400 in the 1982 census), necropsies have been performed whenever possible in cases of suspected SIDS with the aid of the regional SAMU (emergency medical services). Contrary to the prevailing opinion among doctors at that time, parents have only rarely refused a necropsy when the importance of such an investigation is explained to them. All of these necropsies are performed by one pathologist (Dr Tayot of the Rouen University Hospital) and for this and other administrative reasons, necropsies cannot be performed in every 
case, even today. (A necropsy was performed in $65 \%$ of Rouen area cases in 1982.) An analysis of pathological findings in SIDS victims undergoing necropsy in 1980 and 1981 was presented in an unpublished thesis by Delagrée. ${ }^{5}$

Information for years preceding 1982 thus concerns what has been called in the published reports 'sudden unexpected infant death' or 'presumed SIDS'. (The French term is mort inopinée du nourrisson, as oposed to mort inexpliquée du nourrisson, when the SIDS is confirmed by necropsy.)

In this study we obtained death certificates for all babies dying between birth and the age of 1 year in Seine-Maritime between 1978 and 1981. A sudden unexpected infant death (SUID) was defined as a death occurring between the ages of one week and one year where the cause of death was listed either as SIDS (or a variant thereof) or one of the terms shown in Table 1 . These deaths can thus be categorised as post perinatal SUID. Deaths attributed to birth injury or congenital malformations are of course excluded. This definition is in conformity with that of the preceding study, ${ }^{4}$ so as to permit comparison of the SUID rate in the two periods.

Analysis of death certificates produced the names of 207 infants presenting as SUID. We then undertook a comparison between these children and matched controls in respect of data noted on the first medical certificate and included in a computerised information system known as GAMIN. (This system, established in France in 1973 and used in Seine-Maritime since 1975, was designed to select infants presenting medical problems such that either particular medical or social assistance, or both, seemed necessary during early childhood. The names are removed from the computer file when the child reaches 3 years of age so as to preclude concern about the later use of such information.)

Of the 207 children presenting as SUID during this period, we were able to obtain GAMIN computer files on 138 . The death certificate was

Table 1 Terms used on death certificates in cases of sudden unexpected infant deaths (SUID),

Seine-Maritime, 1978 and 1981

\begin{tabular}{lll}
\hline & 1978 & 1981 \\
\hline Sudden infant death syndrome & $31 \%$ & $80 \%$ \\
Other & $69 \%$ & $20 \%$ \\
$\quad$ Apnoea & & \\
Asphyxia, suffocation & & \\
Regurgitation. inhalation of gastric contents & \\
Cardiac or respiratory arrest, asystole & \\
Respiratory failure & \\
Rhinopharyngitis & \\
Cause of death unknown & \\
\hline
\end{tabular}

anonymous (as is permitted by French law) in 29 cases, in five cases (children born in 1977) the names had already been removed from the computer file when the search was begun, and in 35 cases $(17 \%$ of the total) no information could be found in GAMIN concerning the child.

The control children were chosen at random from a list of children of the same sex, born in the same maternity ward (hospital or clinic) in a period from three days before to three days after the birth of the SUID infant. (Cases were matched by clinic of birth so as to attempt to control for socioeconomic factors-including differences between urban and rural areas-and differences between hospital and clinic births, in that hospital births include a large proportion of indigent mothers, as well as of complicated pregnancies.) In two cases no control infant could be found fitting these criteria, and the final study therefore included 136 SUID cases and 136 matched living controls.

Given the large number of SUID infants who could not be included in the GAMIN study, we attempted to ensure that there were no significant differences between the SUID victims included in the study and those who were excluded from it. Using the $\chi^{2}$ test, we found no significant difference between the two groups with regard to the following factors: sex, month of death, age at death, and parents' home address.

A child's first medical certificate, which by law must be completed within the first week of life, contains the following information (in addition to the usual administrative data on the child, his mother, and the social security recipient):

(a) Mother's age and obstetrical history (parity, number of spontaneous abortions, number of stillbirths, number of abnormal pregnancies).

(b) Date of last menstrual period.

(c) Multiplicity of birth.

(d) Length of gestation, presentation at delivery, and length of labour.

(e) Birthweight, length and head circumference at birth, and Apgar score.

In addition, space is provided for a large number of 'signal codes' (critères de signalement) concerning abnormalities of pregnancy (present or previous); labour and delivery; problems during the first week of life (including admission to a neonatal, paediatric intensive care, or paediatric ward); suspected or known congenital malformations; and miscellaneous information such as BCG vaccination, blood phenylalanine testing, and breast feeding. Experience has shown that assiduity in inserting these signal codes varies from one maternity ward to another. Generally speaking, information contained in the rest of the certificate is reliable, with the exception of 
length of labour (the stage not being defined) and the Apgar score (minute not defined).

The statistical techniques used are those designed for the comparison of related samples (in this case, matched pairs - the McNemar test for qualitative variables $\left(\chi^{2}=(A-D)^{2} / A+D\right)$ and the Walsh test, using difference scores, for quantitative variables.

Tests for independent samples were used when analysing birthweight and gestational age separately, because of the small numbers involved and despite the matching of cases and controls, since preliminary calculations had shown that there was no difference in the results of comparing gestation, birthweight, and length at birth in the two groups, whether using statistical tests for related or for independent samples.

\section{Results}

SUID in Seine-Maritime, 1970-81. The Figure shows the infant mortality rate in Seine-Maritime between 1970 and 1981. We note that the SUID rate increased significantly during this period, associated with a significant decrease in the non-SUID mortality rate. Are these changes apparent or real? In as much as the same definition of SUID was used in the two periods, any artifactual change in the SUID rate could only be due to major changes in physician attitudes-that is the attributing of a death to one of the causes which were considered SUID (for example asphyxia) which might previously have been attributed to a specific disease (for example pneumonia). This is possible, but rather unlikely.

It is to be noted, however, that even this recently increased SUID rate $(2.71$ per 1000 live births in the period 1978-81) is well within the range reported in other countries: the average SUID rate obtained from five studies in the US, New Zealand, Great Britain, and Canada being 3.03 per 1000 live births.
These rates are of course higher than the average ( 1.87 per 1000 live births) found in studies of necropsy confirmed SIDS.

Analysis of the total of 207 SUID cases which occurred between 1978 and 1981 gives results which are in general agreement with those of previous studies. We note the usual slight male predominance (57.5\% of our SUID cases) and the preponderance of deaths during the winter months $(45 \%$ of deaths occurring between November and February. In our study, however, as in others, the seasonal variation in SUID cases was not significantly different from that of other infant deaths, $35 \%$ of which occurred during the winter months.

The peak age of death was 2 to 3 months $(29 \%$ of deaths within this age group) and, as expected, the age distribution of SUID and non-SUID differed significantly. This difference remained significant even after excluding those non-SUID deaths where a predominance in the first month would be expected, thereby automatically differentiating these deaths from SUID cases; these included deaths attributed to prematurity, congenital malformations, and neonatal asphyxia (birth injury). (Table 2).

We found no differences, however, either in the sex ratio or in the season of death, between children dying before 12 weeks of age and those dying later, as has been suggested by Fedrick. ${ }^{6}$

The death certificate gave a hospital or clinic as the place of death for 58 children ( $27 \%$ of the total) but in almost all cases the child was taken to the hospital after death, or was declared dead at the hospital after an unsuccessful resuscitation attempt. In two cases the death did in fact occur in hospital: one baby died suddenly while in hospital for an upper respiratory infection, and another baby, born at 31 weeks' gestation, died at 10 weeks of life, the day before he was due to go home. In these infants

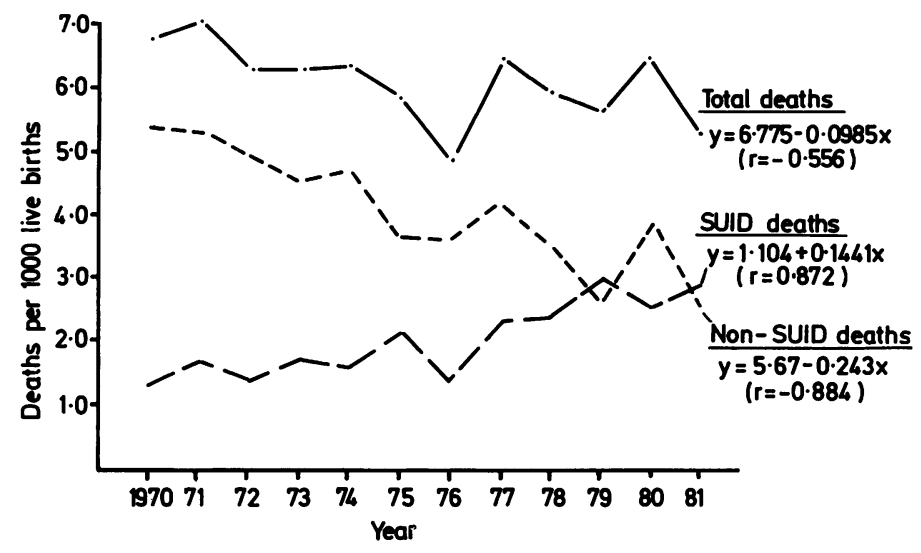

Figure Mortality rates in children aged 1 week to 1 year in Seine-Maritime, 1978-81. 
Table 2 SUID and non-SUID cases in Seine-Maritime, 1978-81

\begin{tabular}{lllllrrr}
\hline & $1 w k-<1 m$ & $1 m-<2 m$ & $2 m-<3 m$ & $3 m-<4 m$ & $4 m-<6 m$ & $6 m-<9 m$ \\
\hline SUID & 14 & 40 & 60 & 35 & 33 & 19 \\
Non-SUID* & 96 & 41 & 27 & 21 & 20 & 17 \\
Corrected non-SUID + & 16 & 13 & 11 & 11 & 9 & 7 \\
\hline
\end{tabular}

* $\chi^{2}=85 \cdot 79$ for $6 \mathrm{df}$; significant at $P \leqslant 0 \cdot 001$.

+ Excluding deaths attributed to prematurity, birth injury, or congenital malformations.

$\chi^{2}=34.08$ for $6 \mathrm{df}$; significant at $P \leqslant 0 \cdot 001$.

necropsies showed no lesions sufficient to explain the deaths.

Previous studies have given contradictory results in respect of the relation between gestation and age at death. Data from Denmark ${ }^{9}$ show no difference between preterm and term babies in age at death. A recent study by Kraus, ${ }^{10}$ however, shows a two week lag in age at death for preterm babies compared with controls. Our results confirm the former study, showing no significant difference in the age of death between SUID babies with a gestational age of 38 weeks or more and the preterm infants, based on information provided on the first medical certificate of these babies. We were able to check the gestation data for 20 of the 27 infants who had been admitted to hospital at birth. Hospital records showed slightly different gestational ages for five of these infants, but these corrections did not change the statistical results.

Similarly, there was no significant correlation between birthweight and age at death $(r=-0 \cdot 221)$. There is a trend toward deviations from the mean for infants of low birthweight (a mean age at death of 19.05 weeks for babies weighing less than $2000 \mathrm{~g}$ at birth) and of high birthweight (mean age of 9.76 weeks for birthweights of $4000 \mathrm{~g}$ or more) but these differences were not statistically significant.

$A$ recent study by Carpenter ${ }^{11}$ has shown variations in the age distribution of SIDS cases with regard to the month of birth. Our analysis shows no statistical difference in age at death between groups of infants classified according to month of birth, but there is a (non significant) tendency towards a higher age of death in children born during the summer months $(20 \cdot 5$ and $20 \cdot 2$ weeks respectively for children born in June and July).

Comparison of SUID cases and controls. Table 3 summarises the results of the comparison between the 136 SUID cases for which a first medical certificate was obtained and the 136 controls matched by sex, date of birth, and maternity clinic. These results are generally in accord with previous studies in other countries, but with certain exceptions.
Table 3 Comparison of SUID cases and living control infants matched for sex, date of birth, and maternity clinic

\begin{tabular}{ll}
\hline Parity & NS \\
Age of mother & NS \\
Gestation & Significantly lower in SUID \\
& cases $(P \leqslant 0 \cdot 05)$ \\
Presentation at delivery & NS \\
Birthweight & Significantly lower in SUID \\
& cases $(P \leq 0 \cdot 001)$ \\
Length at birth & Significantly lower in SUID \\
& cases $(P \leqslant 0 \cdot 05)$ \\
Head circumference at birth & NS \\
Apgar score (minute not specified) & NS \\
Admission to a paediatric ward in the & Significantly more SUID \\
immediate postnatal period & cases $(P \leqslant 0 \cdot 01)$ \\
Breast feeding & NS \\
Abnormalities during pregnancy or delivery & NS \\
Civil status & Significantly more single \\
& mothers among SUID \\
Nationality of mother & cases $(P \leqslant 0 \cdot 05)$ \\
Profession of mother & NS \\
Profession of father & NS \\
\hline
\end{tabular}

NS=not significant.

We were surprised to find no difference between SUID cases and controls in age of mother or parity, since this is in contrast with the results of almost every other previous work. ${ }^{78}{ }^{12-17}$ Further analysis only confirmed our first results: maternal age, when corrected for parity, did not differ significantly in these two groups, and a comparison of the average maternal age of the SUID cases born in 1981 to that of the Seine-Maritime population of live births in that year again showed no significant difference.

The commonly noted difference in the socioeconomic levels of SUID families ${ }^{7} 81314$ was confirmed to only a limited extent by this study, perhaps because the matching technique controlled, in part, for these differences. The proportion of single mothers was significantly higher among SUID cases $(P \leqslant 0 \cdot 05)$, but there were no significant differences between the two groups in mother's nationality or profession, or in the father's profession.

As expected, ${ }^{6-9} 1316$ SUID cases in this study were more premature and had lower birthweights (differences significant at $\mathrm{P} \leqslant 0.05$ and $\mathrm{P} \leqslant 0 \cdot 001$ respectively) than controls.

Since birthweight and gestational age are 
obviously highly correlated, we studied each factor separately in order to analyse its role as a risk factor for SUID. In adjusting for gestation, the Fischer interaction test proved not to be significant, and the birthweights of SUID cases were significantly lower than those of controls, whatever the length of gestation $(P \leqslant 0 \cdot 025)$. (Mean birthweights for each category of gestational age are shown in Table 4.) In adjusting for birthweight, however, we found significant interaction using the Fischer test $(P \leqslant 0 \cdot 05)$ and so an overall test could not be performed. Analysing each category of birthweight separately (Table 5), we found a difference between SUID cases and controls only in the category of infants weighing less than $2500 \mathrm{~g}$ at birth, with SUID cases being significantly more premature than controls $(P \leqslant 0 \cdot 01)$.

These results are in agreement with those of previous studies analysing the role of gestation and birthweight in SIDS, ${ }^{614} 18$ and they emphasise the importance of the association of low birthweight and prematurity as a risk factor in SUID.

As would be expected from the preceding results, this study shows a significant difference in the number of SUID cases and control infants admitted to paediatric wards in the immediate postnatal period: 27 cases and only 10 controls $(P \leqslant 0.01)$. Furthermore, a comparison of these two subgroups using the Mann-Whitney $U$ test shows a significantly $(P \leqslant 0.05)$ shorter gestation and lower birthweight among SUID cases admitted to hospital than controls admitted to hospital. The Apgar score, however, was not significantly different in these two subgroups.

Table 4 Mean birthweight by category of gestation in $S U I D$ cases and matched living control infants

\begin{tabular}{llll}
\hline & Cases & \multicolumn{2}{l}{ Controls } \\
\hline$\leqslant 37$ weeks & 2,168 & 2,692 & \\
$38-39$ weeks & 2.946 & 3,073 & $\mathrm{~F}^{\prime}=6.03$ \\
$40-41$ weeks & 3,360 & 3,432 & $\mathrm{P} \leqslant 0 \cdot 025$ \\
$>41$ weeks & 3.582 & 4,152 & \\
\hline
\end{tabular}

Fischer interaction test not significant.

Table 5 Mean gestation by category of birthweight in SUID cases and matched living control infants

\begin{tabular}{lll}
\hline & Cases & \multicolumn{1}{l}{ Controls } \\
\hline$<2500 \mathrm{~g}$ & $35 \cdot 12$ & $38 \cdot 33 \quad(\mathrm{P} \leqslant 0 \cdot 01)$ \\
$2500-2999$ & $38 \cdot 70$ & $38 \cdot 75$ \\
$3000-3499$ & $39 \cdot 80$ & $39 \cdot 76$ \\
$3500-3999$ & $40 \cdot 50$ & $40 \cdot 32$ \\
$\geqslant 4000$ & $40 \cdot 50$ & $41 \cdot 07$
\end{tabular}

Fischer interaction test significant at $\mathrm{P}<0 \cdot 05$.

\section{Discussion}

Two rather surprising results have been noted in this study. The first concerns the seeming increase in SUID rates in Seine-Maritime in the $1970-81$ period over the preceding decade. In the absence of necropsy data for most deaths, it is obviously impossible to determine whether this increase is real or not, but it is of the utmost importance to obtain data from this period for other regions in France.

The second is the absence of an association between our SUID cases and low maternal age. In the absence of information on this subject in other regions of France, it is difficult to say whether this is simply a statistical aberration, or whether it reflects particular characteristics of SUID in France (particularly in respect of the prenatal care delivery system).

This study confirmed some well established characteristics of SUID, in particular the fact that a significant proportion of these infants had presented problems at birth related to prematurity and low birthweight. Although scoring systems permitting the identification of infants at risk in the general population have been developed, particularly in the seminal work of Carpenter et al, ${ }^{19}{ }^{20}$ financial considerations make the development of such a system difficult in our area. These considerations led us to establish a preliminary (and rudimentary) scoring system involving prematurity and birthweight (Table 6).

The use of criterion 3 (either gestational age less than 37 weeks or birthweight less than $2500 \mathrm{~g}$ ) identifies 22 of the SUID cases and only four of the controls: sensitivity is thus $16 \%$ but specificity $99 \cdot 3 \%$. This scoring system of course identifies a very small number of SUID cases, but also has a very low 'false positive' rate.

It thus seems worthwhile to explore further the possibility of establishing a more precise scoring system involving only those infants presenting with pathology at birth that requires admission to hospital. To this end, two studies are underway at the present time.

Table 6 Preliminary score applied to SUID cases and matched living controls

\begin{tabular}{|c|c|c|c|}
\hline & $S U I D$ & & trols \\
\hline (1) gestation $<37$ weeks & 14 & 3 & \\
\hline (2) Birthweight $<2500 \mathrm{~g}$ & 19 & 2 & \\
\hline (3) (1) or (2) & 22 & 4 & $\left(P \leqslant 0 \cdot(001)^{*}\right.$ \\
\hline (4) (1) and (2) & 11 & 1 & $(P \leqslant 0 \cdot 005) \dagger$ \\
\hline
\end{tabular}


The first involves the analysis of the hospital files on SUID cases who had been admitted to hospital at birth in Seine-Maritime between 1978 and 1981, and a comparison of these infants with living control babies admitted at birth to the same ward and matched for sex, date of admission, and multiplicity of birth. This study seeks to confirm our preliminary results (that is significant differences between SUID cases and controls in gestation and birthweight) as well as to determine other possible differences between these two groups. The scoring system we hope to obtain in this way will then be tested on the population of infants born in Seine-Maritime in 1982 and admitted to hospital at birth.

\section{References}

1 Kahn A, Blum D. Etude intrahospitalière de l'épidémiologie de la mort subite inexpliquée du nourrisson (Bruxelles, 1978-82). Progrès en Néonatologie 1982;2:3-33.

2 Dutruge J, Challamel MJ, Aurand J-M, et al. Particularités de l'étude épidémiologique en cours dans la region lyonnaise. Progrès en Néonatologie 1982;2:47-50.

${ }^{3}$ Alix D, Castel Y, Riche C, et al. Epidémiologie de la mort subite et inexpliquée du nourrisson dans le département du Finistère. Premiers résultats d'une enquête de 1977 à 1981 . LARC Médical 1982;2:675-7.

4 Geffroy D. Syndrome de la mort subite inexpliquée du nourrisson. Revue de la littérature; étude épidémiologique en Seine-Maritime de septembre 1969 à août 1977. Rouen: Thesis, 1979.

5 Delagrée E. Contribution à l'étude anatomique de la mort subite inopinée du nourrisson à propos des observations recueillies à Rouen en 1980 et 1981 . Rouen: Thesis, 1982.

${ }^{6}$ Fedrick J. Sudden unexpected death in infants in the Oxford Record Linkage Area I. An analysis with respect to time and place. II. The mother. III. Details of pregnancy, delivery and abnormalities in the infant. Br J Prev Soc Med 1973;27:217-24 and 1974;28:93-7, 164-71.

${ }^{7}$ Froggatt P, Lynas MA, MacKenzie G. Epidemiology of sudden unexpected death in infants ('cot death') in Northern Ireland. Br J Prev Soc Med 1971;25:119-34.
${ }^{8}$ Kraus JF, Franti CE, Borhani NO. Discriminatory risk factors in post-neonatal sudden unexpected death. Am J Epidemiol 1972;96:328-33.

9 Jorgensen T, Biering-Sorensen F, Hilden J. Sudden infant death in Copenhagen, 1956-1971, III. Perinatal and perimortal factors. Acta Paediatr Scand 1979;68:11-22.

10 Kraus JF. Methodologic considerations in the search for risk factors unique to Sudden Infant Death Syndrome. In: Tildon JT, Roeder LM, Steinschneider A, eds. Sudden infant death syndrome. Baltimore: Academic Press, 1983:43-58.

"Carpenter RG. The search for practical predictors of risk. In: Tildon JT, Roeder LM, Steinschneider A, eds. Sudden infant death syndrome. Baltimore: Academic Press, 1983:29-42.

12 Kraus AS, Steele R, Thompson MG, et al. Further epidemiological observations on sudden unexpected death in infancy in Ontario. Can J Public Health 1971;62:210-9.

13 Watson E, Gardner A, Carpenter RG. An epidemiological and sociological study of unexpected death in infancy in nine areas of southern England, I. Epidemiology. II. Symptoms and patterns of care. Med Sci Law 1981;21:78-104.

14 Naeye RL, Ladis B, Drage JS. Sudden Infant Death Syndrome: a prospective study. Am J Dis Child 1976;130:1207-10.

15 Biering-Sorensen F, Jorgensen T, Hilden J. Sudden infant death in Copenhagen, 1956-1971. II. Social factors and morbidity. Acta Paediatr Scand 1979;68:1-9.

16 Arsenault PS. Maternal and antenatal factors in the risk of Sudden Infant Death Syndrome. Am J Epidemiol 1980;111: 279-84.

17 Peterson DR. Sudden Infant Death Syndrome and maternal age. JAMA 1982;247:2250-2.

18 Standfast SJ, Jereb S, Janerich DT. The epidemiology of Sudden Infant Death in upstate New York. II. Birth characteristics. Am J Public Health 1980;70:1061-7.

19 Carpenter RG, Gardner A, Jepson M, et al. Prevention of unexpected infant death: evaluation of the first seven years of the Sheffield Intervention Programme. Lancet 1983;i:723-7.

20 Carpenter RG. Risk score-a tool for prevention and evaluation. In: Tildon JT, Roeder LM, Steinschneider A, eds. Sudden infant death syndrome. Baltimore: Academic Press, 1983; 705-18.

Correspondence to Dr M Wagner, Department of Emergency Medicine, Wright State University School of Medicine, PO Box 927, Dayton, Ohio 45401, USA.

Received 26 July 1984 